\title{
Modified composite graft using diced autogenous cartilage for amputated ear reconstruction: A case
} report

\section{Ha Hyun Yu, Youngwoong Choi}

Department of Plastic and Reconstructive Surgery, Sanggye Paik Hospital, Inje University College of Medicine, Seoul, Korea
Trauma to the auricle is common given its prominent position, and various methods for ear reconstruction exist. Herein, we present our experience of ear reconstruction using diced autogenous cartilage. A 72-year-old woman fell from a 1-m height, damaging her ear in the process. The ear helix, which was approximately $3.5 \times 3 \mathrm{~cm}^{2}$ in size, was amputated. The cartilage was diced into 1-mm pieces. The detached skin was made into a pocket and filled with the diced cartilage. Molding was performed with tie-over dressings on the anterior and posterior areas of the scaphoid fossa. Ten days post-surgery, the wound showed signs of successful recovery, and the contour of the ear helix was maintained. Ten months later, the cartilage in the damaged ear helix was intact. Conventional composite grafts on amputated ears have size limitations and exhibit significant resorption, and loss of anatomical structures and stability often occur. In this case, the operating time required to complete the composite graft was short, and molding the contour was not complex. The original ear structure was maintained over the long term and did not require an additional operation for aesthetic purposes. We believe that this is a useful method for the reconstruction of an amputated ear.

Keywords Ear / Cartilage / Surgery / Wounds and injuries

\section{INTRODUCTION}

The diced cartilage graft was first described in 1941 by Young [1]. Currently, diced cartilage grafts are used for rhinoplasty because they reduce the need for harvesting cartilage grafts from other sites, can be shaped with the fingers, and have a very low risk of postoperative malalignment or visibility $[2,3]$.

Given the prominent position of the ear on the side of the head and its delicate skin covering a complex cartilaginous framework,

Received: Jan 21, 2019 Revised: Mar 4, 2019 Accepted: Mar 5, 2019 Correspondence: Youngwoong Choi Department of Plastic and Reconstructive Surgery, Sanggye Paik Hospital, Inje University College of Medicine, 1342 Dongil-ro, Nowon-gu, Seoul 01757, Korea Tel: +82-2-950-1048, Fax: +82-2-932-6373, E-mail: pshero2@naver.com Copyright () 2019 The Korean Society for Aesthetic Plastic Surgery. This is an Open Access article distributed under the terms of the Creative Commons Attribution Non-Commercial License (http://creativecommons.org/licenses/by-nc/4.0/) which permits unrestricted non-commercial use, distribution, and reproduction in any medium, provided the original work is properly cited. $\quad w w w . e-a a p s . o r g$ auricular trauma is relatively frequent [4]. Treatment of minor ear trauma follows a different set of principles [5]. In contrast, methods of treatment for amputated ears vary from direct replantation, microvascular repair, and the pocket method to secondary reconstruction [6]. However, there is no standard treatment of choice, and existing methods each have advantages and disadvantages. Herein, we present our experience of a reconstruction method using diced cartilage that led to a satisfactory aesthetic outcome in a patient with partial ear amputation.

\section{CASE REPORT}

A 72-year-old woman fell from a height of $1 \mathrm{~m}$, and a flowerpot crushed her right ear. Her right ear helix was amputated, including the cartilage. The affected portion was approximately $3.5 \times 3 \mathrm{~cm}^{2}$ in size (Fig. 1).

Five hours after the trauma, a composite graft procedure was performed under general anesthesia. Before the procedure, the amputated ear tissue was stored in a refrigerator covered with saline- 

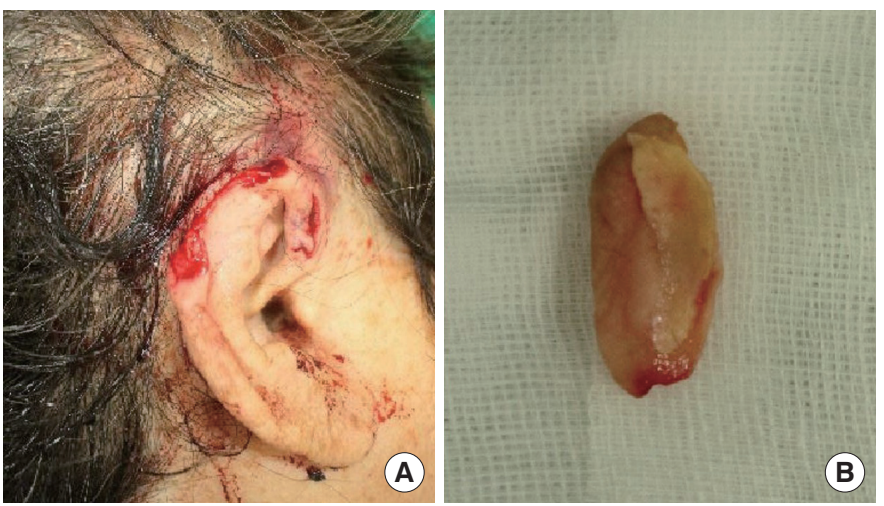

Fig. 1. Amputated ear. (A) A 72-year-old woman fell from a 1-m height, and her right ear was crushed by a flowerpot. (B) The amputated helix containing the cartilage portion.
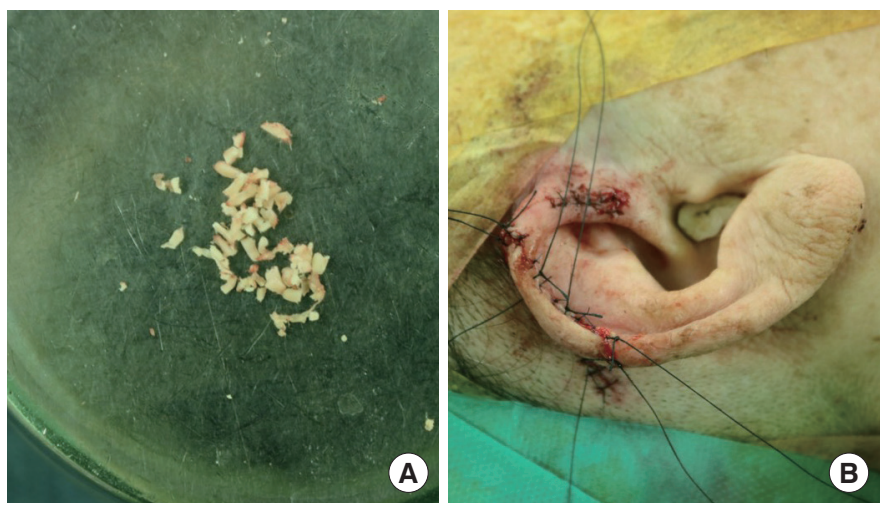

Fig. 2. Intraoperative images. (A) The separated cartilage was diced into 1-mm pieces using a no. 11 blade. (B) The skin was sutured, formed into a pocket, and filled with the diced cartilage.

soaked gauze. Following debridement of the damaged portion and removal of dirt particles, the margin of amputation was thoroughly cleansed using continuous saline and betadine irrigation. The amputated part was separated into cartilage and skin. The cartilage portion was diced into 1-mm pieces using a no. 11 blade. The skin was sutured around the wound using 6-0 nylon, and a pocket was made. The diced cartilage was inserted into the pocket. Molding was performed using a tie-over dressing on the anterior and posterior areas of the scaphoid fossa (Fig. 2). No adjuvant treatment modalities such as hyperbaric oxygen therapy or ice-pack cooling were employed postoperatively.

Nine days after the operation, the tie-over dressing was removed. There was no sign of hematoma or severe necrosis that would require a subsequent operation. Ten days after the surgery, the wound showed signs of successful recovery, and the shape of the ear helix was maintained (Fig. 3). The patient was followed-up regularly at the outpatient department.

Ten months after implementation of the composite graft using

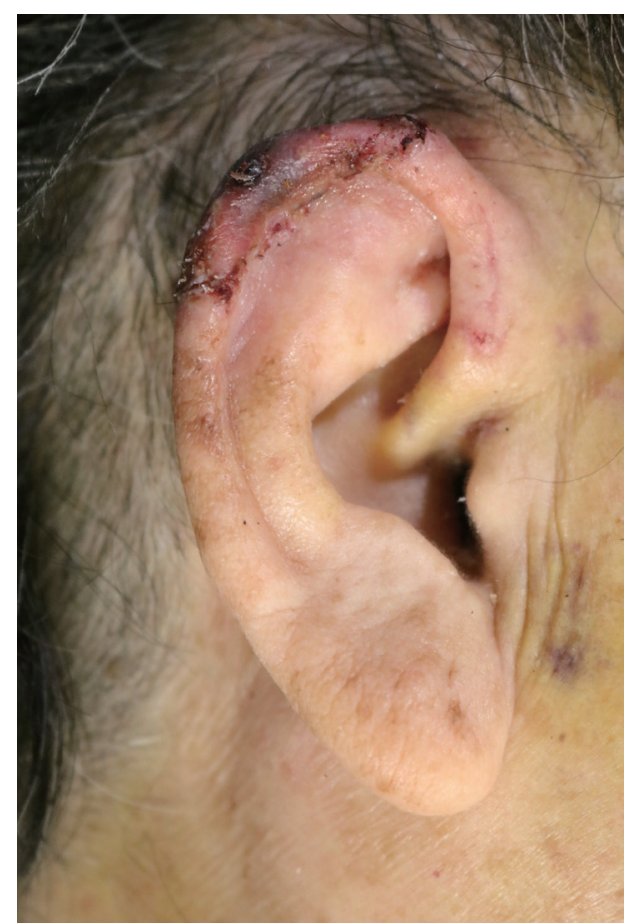

Fig. 3. Ten days after the operation. The wound showed good recovery at 10 days after the composite grafting procedure with diced cartilage.

diced cartilage, the complex contour of the ear was maintained. The diced cartilage had not been not completely absorbed, but instead formed the structure of the ear helix (Fig. 4).

\section{DISCUSSION}

Auricular trauma is relatively frequent due to the prominent position of the ear on the side of the head, and the delicate skin covering a complex cartilaginous framework [4]. Treatment of ear trauma varies by size, depth, and cause of injury [5]. There are several methods of treatment for an amputated ear, including direct reattachment, the pocket method, composite grafts, and microvascular repair [6,7]. In this case, the amputated ear was reconstructed via a composite graft. Microvascular repair was not suitable because the ear was crushed and not large enough for this procedure. Ihrai et al. [8] recommended the pocket method for small ear amputations $(<15 \mathrm{~mm})$ and for those that do not involve the lobule. While the results achieved by applying the pocket method are aesthetically superior to those observed with other methods, this approach requires a second operation and may occasionally necessitate the application of a skin graft on the posterior aspect. Conversely, a composite graft reduces the operating time, but survival of the amputated tissue and cartilage is not certain. Brown and Cannon [9] suggested that the size limitation for successful composite grafting is approximately $1 \mathrm{~cm}$. In the present case, the amputated portion 

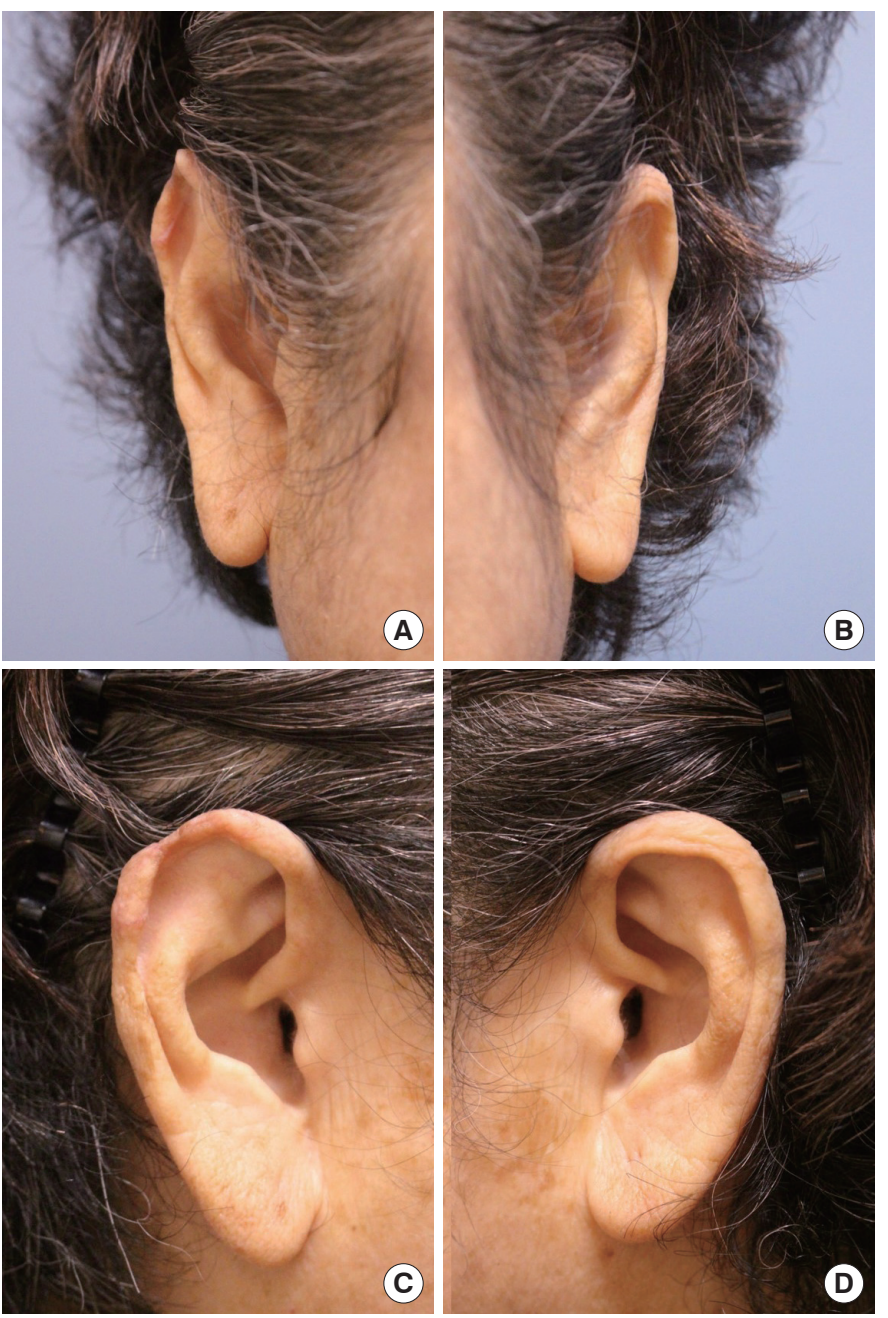

Fig. 4. Ten months after the operation. The overall ear complexity and contour were maintained at 10 months after application of the composite graft with diced cartilage. (A) Frontal view of the operated ear. (B) Frontal view of opposite normal ear. (C) Side view of the operated ear. (D) Side view of the opposite normal ear.

was approximately $3.5 \times 3.0 \mathrm{~cm}^{2}$. Large amputations are difficult to repair by a conventional composite graft. Therefore, in our case, we used the diced cartilage method in combination with a composite graft.

Cartilage is a unique tissue because of its low metabolic rate and avascular structure, and because its nutrition is provided by tissue fluid diffusion [10]. After repair of the amputated ear, significant resorption of the reattached auricular cartilage can occur [11]. Kolodzynski et al. [12] decided not to use the cartilage of the lost segment in the reconstruction of a damaged ear because of extensive resorption. Further, in the report by Steffen et al. [13], the cartilage of a repaired ear lost its complex anatomy and stability after surgery.

In contrast, Young [1] and Peer [14] reported the survival of diced cartilage with interspersed fibrous tissue, resulting in a solid sheet of opaque cartilage-like material after a successful grafting procedure. McLaughlin [15] reported that in successful ear grafts, erythrocytes usually infiltrate the graft tissue successfully within a few days of the procedure. Therefore, revascularization occurred relatively easily in our patient, as the diced cartilage nestled within the skin pocket enabled early ingress of erythrocytes and nutrients from the bloodstream into the graft. Grafts using diced cartilage are moldable and have a low risk of rejection compared to synthetic material. In the present case, the amputated ear was repaired by a composite graft with diced cartilage from the damaged ear. This method allowed the shape of the ear helix and the scaphoid fossa to be easily molded, and structural stability was well maintained over the long term.

Although the overall shape of the ear helix was retained, there was a minor depression in the central area of the composite graft surface in comparison with the appearance of the contralateral ear (Fig. 4). This may have occurred due to compression from the tieover dressing applied on the anterior and posterior areas of the scaphoid fossa to fix the graft in position. As a result, the blood supply to the central area may have been limited, leading to a reduction in the volume of the graft tissue. Additionally, the molding with two tie-over dressings did not achieve concavity between the ear helix and the scaphoid fossa. In the future, this can be prevented by studying and refining the proper technique for molding the skin pocket surrounding the diced cartilage.

In conclusion, ear reconstruction is a difficult technique, as it requires maintaining the highly detailed anatomic complexity of the ear, as well as preserving the thin soft tissue. An ideal method for managing ear trauma cases would allow the original shape of the ear to be maintained. Conventional composite grafts for amputated ears have size limitations and are vulnerable to significant cartilage resorption, and the loss of anatomical features and stability often occur. The diced cartilage method is a relatively simple and short procedure for treating an amputated ear. In addition, this case showed good outcomes in terms of cartilage survival, the quality of ear complexity, and esthetics. We believe that this technique will be useful for repairing amputated ears.

\section{NOTES}

\section{Conflict of interest}

No potential conflict of interest relevant to this article was reported.

\section{Ethical approval}

The study was performed in accordance with the principles of the Declaration of Helsinki.

\section{Patient consent}

The patient provided written informed consent for the publication and the use of her images. 


\section{ORCID}

Ha Hyun Yu

https://orcid.org/0000-0002-0454-5070

Youngwoong Choi

https://orcid.org/0000-0002-2211-2981

\section{REFERENCES}

1. Young F. Autogenous cartilage grafts. Surgery 1941;10:7.

2. Daniel RK, Calvert JW. Diced cartilage grafts in rhinoplasty surgery. Plast Reconstr Surg 2004;113:2156-71.

3. Erol OO. The Turkish delight: a pliable graft for rhinoplasty. Plast Reconstr Surg 2000;105:2229-41.

4. Shaye D, Sykes JM. Reconstruction of acquired auricular deformity. Oper Tech Otolayngol Head Neck Surg 2011;22:47-52.

5. Weerda H. Surgery of the auricle: tumors-trauma-defects-abnormalities. 1st ed. New York: Thieme; 2006.

6. Steffen A, Frenzel H. Trauma management of the auricle. Facial Plast Surg 2015;31:382-5.

7. Kind GM. Microvascular ear replantation. Clin Plast Surg 2002;29:23348.
8. Ihrai T, Balaguer T, Monteil MC, et al. Surgical management of traumatic ear amputations: literature review. Ann Chir Plast Esthet 2009; 54:146-51.

9. Brown JB, Cannon B. Composite free grafts of skin and cartilage from the ear. Surg Gynecol Obstet 1946;82:253-5.

10. Peer LA. Cartilage grafting. Br J Plast Surg 1954;7:250-62.

11. Mladick RA. Salvage of the ear in acute trauma. Clin Plast Surg 1978;5: 427-35.

12. Kolodzynski MN, Kon M, Egger S, et al. Mechanisms of ear trauma and reconstructive techniques in 105 consecutive patients. Eur Arch Otorhinolaryngol 2017;274:723-8.

13. Steffen A, Katzbach R, Klaiber S. A comparison of ear reattachment methods: a review of 25 years since Pennington. Plast Reconstr Surg 2006;118:1358-64.

14. Peer LA. Diced cartilage grafts: new method for repair of skull defects, mastoid fistula and other deformities. Arch Otolaryngol 1943;38:15665.

15. Mclaughlin CR. Composite ear grafts and their blood supply. Br J Plast Surg 1954;7:274-8. 